ISSN. 2775-4324 (Online)

Journal of Physical Activity and Sports

Volume 2, Nomor 1, Bulan 2021, 64-70

Journal of Physical Activity and Sports

\title{
PERBEDAAN PUKULAN LOB BERPOLA DAN PEMBERIAN LOB TAK LANGSUNG TERHADAP KETEPATAN PUKULAN LOB DALAM PERMAINAN BULUTANGKIS PADA ATLET PEMULA PUTRA PB. LINDU AJI NGALIYAN
}

\author{
Muhammad Shofiana ${ }^{1 *}$, Fajar Ari Widiatmoko ${ }^{2 *}$ Asep Ardiyanto ${ }^{3}$ \\ ${ }^{1}$ Universitas PGRI Semarang.Semarang 50122, Indonesia \\ ${ }^{2}$ Universitas PGRI Semarang.Semarang 50122, Indonesia \\ ${ }^{3}$ Universitas PGRI Semarang.Semarang 50122, Indonesia \\ * Muhammad Shofiana. E-mail: Muhammadshofiana2197@gmail.com
}

Received: 16/12/2020; Revised: 22/4/2021; Accepted: 29/4/202

\begin{abstract}
The problems in this study were (1) whether there was a difference in the effect of patterned lob training and indirect lob treatment on the accuracy of lob strokes and (2) which one was better between patterned lob training and indirect lob practice. While the objectives of this study were (1) to determine the effect of patterned lob training and indirect lob on the accuracy of lob stroke accuracy (2) to determine which one was better patterned lob and indirect lob. In accordance with this background, this research is experimental.

This type of research is quantitative, with a Two Group Pretest Posttest design. The population in this study athletes PB Lindu Aji Ngaliyan, amounting to 53 people and a sample of 20 people. In taking the sample using purposive sampling technique. There were 2 types of variables studied in this study, namely patterned lob training and indirect lob as the independent variable and the accuracy of the lob as the dependent variable. The research instrument used the lob punch test. Furthermore, the data obtained was then entered into SPSS.

This research shows. the results of the Independent Sample T-Test hypothesis test obtained the value of tcount (2.182) and the value of Sig. Thus you can do patterned lob training and give indirect lob gives better results for the accuracy of the lob stroke is the pattern lob rolling exercise.

The conclusions of this study are (1) there is an effect of patterned lob training on increasing lob accuracy (2) there is an effect of indirect lob training on increasing lob accuracy (3) there is a difference between the effect of patterned lob strokes and indirect lob in accuracy. The lob stroke and patterned lob training method were better than the indirect lob training method in increasing the accuracy of the lob stroke. Suggestions in this research (1) For novice athletes to continue to strive to improve the accuracy of lob strokes (2) For coaches to always provide an effective and efficient training program to their athletes, especially training programs to improve the accuracy of lob strokes, namely by providing lob stroke training. patterned (3) For further researchers, it is necessary to add other variables so that studies that examine methods to improve the accuracy of lob hits are wider.
\end{abstract}

Keywords: patterned lob, indirect lob, precision lob, badminton.

\footnotetext{
Abstrak

Muhammad Shofiana "Perbedaan Pukulan Lob Berpola dan Pemberian Lob Tak Langsung Terhadap Ketepatan Pukulan Lob Dalam Permainan Bulutangkis Pada Atlet Pemula Putra PB. Lidu Aji Ngaliyan” Fakultas Pendidikan Ilmu Pengetahuan Sosial dan Keolahragaan, Universitas PGRI Semarang, 2020.
} 
Permasalahan dalam penelitian ini adalah (1) apakah ada perbedaan pengaruh latihan pukulan $l o b$ berpola dan pemberian $l o b$ tak langsung terhadap ketepatan pukulan lob dan (2) mana yang lebih baik diantara latihan pukulan lob berpola dan pemberian lob tak langsung. Sedangkan tujuan penelitian ini adalah (1) mengetahui pengaruh dari latihan pukulan lob berpola dan pemberian lob tak langsung terhadap ketepatan ketepatan pukulan lob (2) mengetahui manakah yang lebih baik pukulan $l o b$ berpola dan pemberian $l o b$ tak langsung. Sesuai dengan latar belakang tersebut maka penelitian ini bersifat eksperimen.

Jenis penelitian yang digunakan adalah kuantitatif, dengan design Two Group Pretest Posttest. Populasi dalam penelitian ini atlet PB Lindu Aji Ngaliyan yang berjumlah 53 orang dan sampel 20 orang. Dalam pengambilan sampel menggunakan teknik purposive sampling. Varibel yang dikaji dalam penelitian ini ada 2 macam yaitu latihan pukulan $l o b$ berpola dan pemberian lob tak langsung sebagai variabel bebas dan ketepatan pukulan lob sebagai variabel terikat. Instrumen penelitian menggunakan tes pukulan lob. Selanjutnya data yang diperoleh kemudian dimasukan ke dalam SPSS.

Penelitian ini menunjukan. hasil uji hipotesis Independent Sample T-Test diperoleh nilai Thitung $(2,182)$ dan nilai Sig. Dengan demikian dapat dijelaskan latihan pukulan lob berpola dan pemberian lob tak langsung memberikan hasil lebih baik terhadap ketepatan pukulan $l o b$ adalah latihan pukulan $l o b$ berpola.

Kesimpulan penelitian ini adalah (1) ada pengaruh latihan pukulan lob berpola terhadap peningkatan ketepatan pukulan lob (2) ada pengaruh latihan pemberian lob tak langsung terhadap peningkatan ketepatan pukulan $l o b$ (3) terdapat perbedaan antara pengaruh pukulan $l o b$ berpola dengan pemberian $l o b$ tak langsung dalam ketepatan pukulan $l o b$ serta metode latihan pukulan $l o b$ berpola lebih baik dibanding latihan pemberian lob tak langsung dalam meningkatkan ketepatan pukulan lob. Saran dalam penelitan ini (1) Bagi atlet pemula agar terus berusaha meningkatkan ketepatan pukulan lob (2) Bagi pelatih agar selalu memberikan program latihan yang efektif dan efesien kepada atletnya, khususnya program latihan untuk meningkatkan ketepatan pukulan $l o b$, yaitu dengan cara memberikan latiham pukulan lob berpola (3) Bagi peneliti selanjutnya, supaya menambahkan varibael lain sehingga penelitian yang mengkaji tentang metode untuk meningkatkan ketepatan pukulan lob lebih luas.

Kata Kunci: pukulan $l o b$ berpola, pemberian $l o b$ tak langsung, ketepatan pukulan $l o b$, bulutangkis.

\section{PENDAHULUAN}

Olahraga merupakan aktivitas gerak fisik yang sudah menjadi kebutuhan manusia karena dengan tingkah laku atau aktivitas olahraga yang teratur, terukur dan terarah maka akan menjadikan jiwa dan raga manusia menjadi lebih baik. "Olahraga adalah segala kegiatan yang sistematis untuk mendorong, membina, serta mengembangkan potensi jasmani, rohani, dan sosial" (Asnaldi, 2016) (Sistem keolahragaan nasional, 2005:4). Olahraga adalah penggunaan raga manusia yang diolah untuk melakukan aktifitas-aktifitas karena manusia itu terbagi menjadi dua bagian yaitu jiwa sebagai penggerak dan raga sebagai alat gerak. Melihat penjelasan diatas jelas bahwa olahraga yang ingin dikembangkan harus dilakukan secara 
sistematis, terukur dan terarah sehinga dapat membina karakter yang lebih baik dan mampu mengembangkan potensi jamani dan rohani serta berjiwa sosial.

Menurut (Aksan, 2012:14) Bulutangkis atau badminton adalah suatu olahraga raket yang dimainkan oleh dua orang (untuk tunggal) atau dua pasangan (untuk ganda) yang berlawanan di bidang lapangan yang dibagi dua oleh sebuah jaring (net). Bulutangkis adalah suatu permainan yang tidak dipantulkan dan harus dimainkan di udara, sehingga permainan ini merupakan permainan cepat yang membutuhkan gerak reflek yang baik dan tingkat kebugaran yang tinggi. Pemain bulutangkis juga dapat mengambil keuntungan dari permainan ini dari segi sosial, hiburan dan mental ditunjukkan banyaknya yang bermain bulutangkis baik diruangan tertutup (indoor) dan lapangan terbuka (outdoor). Olahraga bulutangkis juga merupakan salah satu andalan Indonesia untuk meraih prestasi di turnamenturnamen nasional, internasional yang dapat membawa nama baik negara Indonesia. Olahraga ini menjadi olahraga yang sangat populer dan diminati masyarakat Indonesia. Orang-orang yang melakukan permainan ini dengan berbagai tujuan diantaranya adalah sebagai berikut: 1) Olahraga rekreasi, 2) Olahraga Pendidikan, 3) Olahraga kesehatan atau media untuk meningkatkan kesegaran jasmani dan 4) Olahraga prestasi.

Setiap cabang olahraga memiliki teknik dasar yang harus dikuasi terlebih dahulu, begitu juga dengan olahraga bulutangkis, untuk dapat bermain bulutangkis maka seorang pemain harus menguasai teknik dasar seperti cara memegang raket, gerakan kaki (footwork), dan teknik dasar pukulan. (Akbar, Hidasari, \& Haetami, 2017:2) macam-macam teknik dasar pukulan dalam permainan bulutangkis adalah servis panjang, servis pendek, lob, smash, dropshot, chop, drive, dan netting. Untuk dapat menguasi teknik-teknik dasar tesebut perlu kaidah-kaidah yang harus dilaksanakan dalam latihan. Teknik dasar pukulan merupakan jantung dalam permainan bulutangkis karena untuk memulai permainan bulutangkis adalah memukul shuttlecock dengan menggunakan raket. Setelah penguasaan teknik dasar tersebut dikuasai, maka pemain bulutangkis diharuskan menguasai teknik pukulan, di antaranya adalah pukulan service, lob, dropshot, drive, dan smash. Servis adalah pukulan pembuka permainan bulutangkis dimana seorang pemain melakukan pukulan pada shuttlecock untuk mengawali jalannya perrmainan. Lob adalah pukulan yang dilakukan dengan kekuatan terletak pada daya ledak lengan untuk menghasilkan pukulan keras dan akurat kebelakang garis lapangan lawan, denga tujuan untuk merusak pertahanan lawan. Dropshot adalah pukulan yang dilakukan hampir menyerupai pukulan smash, hanya saja shuttlecock dipukul 
dengan dorongan dan sentuhan yang halus. Drive adalah pukulan yang dilakukan dengan menerbangkan shuttlecock secara mendatar, biasanya pukulan ini sering digunakan dalam permainan ganda/double. Smash adalah pukulan yang dilakukan menukik kearah lawan dan dilakukan dengan kekuatan penuh. Jenis pukulan ini identic sebagai pukulan menyerang karena bertujuan untuk mematikan lawan.

Pukulan overhead lob dengan pola pengumpan adalah jenis pola pukulan yang bisa digunakan dalam latihan biasa, dimana salah satu pemain memberikan umpan untuk melakukan pukulan overhead lob. Pukulan overhead lob dengan pola bergantian biasa digunakan dalam latihan, dengan kedua pemain bisa saling memberika umpan untuk melakukan pukulan overhead lob dalam jumlah tertentu. PB Lindu Aji Ngaliyan merupakan salah satu dari klub-klub bulutangkis yang ada di semarang yang pemainnya dalam melakukan pukulan overhead lob masih tergolong kurang menguasi teknik pukulan overhead lob ini, khususnya untuk hasil pukulan overhead lob sering kali nanggung atau kurang tepat sasaran karena keterlambatan anak menarik/menggerakkan siku dan bahu ke belakang, sehingga ayunan terlambat dilakukan dan raket menyudut ke atas dan posisi badan yang salah. Hal ini mengakibatkan pukulan yang kurang keras dan tidak terarah sehingga shuttlecock tidak tepat pada daerah pukulan overhead lob yang membuat arah shuttlecock menjadi tanggung.

Hasil pengamatan peneliti di PB. Lindu Aji pelatih sudah baik dalam melakukan latihan fisik, teknik dan taktik dalam permainan bulutangkis, hanya kurang memperhatikan dalam latihan teknik terutama dalam pukulan lob. Hal tersebut tentunya membuat atlet kurang maksimal dalam mengikuti kejuaran-kejuaran, karena pukulan lob modal utama seorang pemain tunggal/single. Melihat atlet yang kategorinya masih pemula dan anak usia dini saat bertanding dan latihan masih ada pemain yang kurang benar saat melakukan dan hasil kurang maksimal dalam pukulan overhead lob (forehand lob).

\section{METODE}

Metode peneltian yang digunakan adalah penelitian eksperimental menggunakan desain penelitian two-group pretest-posttest design instrumen yang digunakan adalah pukulan overhead lob dalam permainan bulutangkis 


\section{HASIL DAN PEMBAHASAN}

\section{Hasil Penelitian}

Tujuan dari penelitian ini adalah untuk meningkatkan ketepatan pukulan lob dalam bulutangkis $L o b$ adalah pukulan yang dilakukan dengan kekuatan terletak pada daya ledak lengan untuk menghasilkan pukulan keras dan akurat kebelakang garis lapangan lawan dengan tujuan untuk merusak pertahanan lawan. Pukulan $l o b$ berpola dan pemberian lob tak langsung sama baiknya dalam meningkatkan ketepatan pukulan lob,

Hasil peningkatan lebih tinggi menggunakan metode pukulan lob berpola dari pada pemberian $l o b$ tak langsung, maka dapat dismpulkan bahwa pukulan lob berpola lebih baik dalam meningkatkan hasil ketepatan pukulan lob dalam permainan bulutangkis.

\section{Pembahasan Penelitian}

Pukulan $l o b$ sangat sering dilakukan oleh setiap pemain bulutangkis. Pukulan $l o b$ sangat penting untuk mengendalikan permainan bulutangkis, sangat baik untuk mengatur pola permainan entah itu menyerang atau membenahi posisi sulit saat mendapat tekanan dari lawan. Lob adalah pukulan yang dilakukan dengan kekuatan terletak pada daya ledak lengan untuk menghasilkan pukulan keras dan akurat kebelakang garis lapangan lawan, denga tujuan untuk merusak pertahanan lawan. Dalam penelitian ini, peneliti mengambil studi kasus mengenai ketepatan pukulan lob pada atlet di PB Lindu Aji Ngaliyan, teknik pukulan lob yang diterapkan yaitu pukulan $l o b$ berpola dan pemberian lob tak langsung. Subjek penelitian yaitu 10 atlet pemula putra di PB Lindu Aji yang diterapkan metode pukulan lob berpola dan 10 atlet pemula putra di PB Lindu Aji yang diterapkan metode pemberian lob tak langsung.

Hasil uji hipotesis untuk menjawab tujuan penelitian apakah terdapat pengaruh pemberian pukulan lob berpola dengan menggunakan Paired Sample T-Test, diperoleh nilai $\mid$ Thitung $|=|-11,699 \mid>$ Thitung $(2,262)$ dan nilai Sig. $(0,000)<\alpha(0.05)$ yang berarti ada pengaruh pemberian pukulan $l o b$ berpola terhadap peningkatan ketepatan pukulan lob atlet di PB Lindu Aji Ngaliyan. Dimana terjadi peningkatan rata-rata hasil ketepatan pukulan lob sebesar 20,59\% dari rata-rata pretest sebesar 51,00 naik menjadi rata-rata posttest sebesar 61,50 .

Hasil uji hipotesis untuk menjawab tujuan penelitian apakah terdapat pengaruh pemberian lob tak langsung dengan menggunakan Paired Sample T-Test, diperoleh nilai $\mid$ Thitung $|=|-4,993 \mid>$ Thitung $(2,262)$ dan nilai Sig. $(0,001)<\alpha(0.05)$, yang berarti ada 
Perbedaan Pukulan Lob Berpola Dan Pemberian Lob Tak Langsung Terhadap Ketepatan Pukulan Lob Dalam Permainan Bulutangkis Pada Atlet Pemula Putra

Pb. Lindu Aji Ngaliyan

Muhammad Shofiana 1 *, Fajar Ari Widiatmoko 2 *Asep Ardiyanto 3

pengaruh pemberian $l o b$ tak langsung terhadap peningkatan ketepatan pukulan $l o b$ atlet di PB Lindu Aji Ngaliyan. Dimana terjadi peningkatan rata-rata hasil ketepatan pukulan $l o b$ sebesar $16,46 \%$ dari rata-rata pretest sebesar 39,50 naik menjadi rata-rata postetst sebesar 46,00.

Perbedaan pengaruh pemberian pukulan $l o b$ berpola dan pemberian $l o b$ tak langsung terhadap peningkatan ketepatan pukulan lob atlet di PB Lindu Aji Ngaliyan dapat dilihat dari hasil uji hipotesis Independent Sample T-Test diperoleh nilai Thitung $(2,182)>$ Thitung $(2,10092)$ dan nilai Sig. $(0,043)<\alpha(0.05)$, yang berarti terdapat perbedaan yang signifikan antara pengaruh pukulan $l o b$ berpola dan pemberian $l o b$ tak langsung terhadap peningkatan ketepatan pukulan lob atlet di PB Lindu Aji Ngaliyan. Dimana rata-rata hasil ketepatan pukulan $l o b$ berpola sebesar 61,50 dan rata-rata hasil ketepatan pemberian lob tak langsung sebesar 46,00. Karena rata-rata dan peningkatan hasil ketepatan pukulan lob berpola lebih tinggi daripada pemberian lob tak langsung, maka dapat diambil kesimpulan bahwa pukulan $l o b$ berpola lebih efektif dibandingkan pemberian lob tak langsung dalam meningkatkan hasil ketepatan pukulan lob dalam permainan bulutangkis di PB Lindu Aji Ngaliyan.

Metode pukulan lob berpola memiliki beberapa keuntungan yaitu memudahkan dalam hal ketepatan atau perkenaan antara kepala shuttlecock dengan raket sehingga memudahkan perkenaan atau titik temu antara shuttlecock dengan raket, mudah dalam hal melakuan pukulan dengan teknik pukulan yang benar, mampu meningkatkan koordinasi yang baik, antara gerakan kaki (foot work) dengan pukulan lob, penguasaan lapangan yang baik karena atlet dituntut untuk bergerak cepat mengejar arah shuttlecock untuk melakukan pukulan lob, lebih aktif hal ini yang dimaksud atlet lebih banyak gerak ketimbang pasif, mudah untuk menumbuhkan rasa percaya diri, karena posisi shutllecock sesuai dengan jangkauan atlet, maka atlet dapat melakukam pukulan lob dengan lebih sehingga rasa percaya diri bahwa atlet mampu memukul dengan tepat akan tumbuh.

Ada beberapa hal yang terjadi dalam penelitian ini, sehingga bisa mempengaruhi pelaksanaan dan hasil penelitian, yaitu faktor kesungguhan dan kehadiran dalam latihan. Namun hal tersebut dapat diatasi oleh peneliti, dengan adanya koordinasi yang baik antara pelatih, sampel dan peneliti dalam memberikan pengertian dan motivasi pada anak agar bersungguh-sungguh dalam mengikuti program latihan. Semua masalah di atas mempengaruhi jalannya penelitian dan hasil penelitian dapat diatasi oleh peneliti maka untuk pelaksanaan dapat berjalan hasil yang dicapai sesuai yang diharapkan peneliti. 


\section{KESIMPULAN}

Kesimpulan ada pengaruh latihan pukulan lob berpola terhadap peningkatan ketepatan pukulan $l o b$ atlet pemula puta PB. Lindu Aji Ngaliyan. Ada pengaruh latihan pemberian lob tak langsung terhadap peningkatan ketepatan pukulan lob atlet pemula puta PB. Lindu Aji Ngaliyan. Terdapat perbedaan antara pengaruh latihan pukulan lob berpola dengan latihan pemberian lob tak langsung dalam peningkatan ketepatan pukulan lob atlet pemula puta, serta metode latihan pukulan $l o b$ berpola lebih efektif dibanding latihan pemberian lob tak langnsung dalam upaya meningkatkan ketepatan pukulan $l o b$ atlet pemula putra PB. Lindu Aji Ngaliyan.

Saran Bagi atlet bulutangkis PB. Lindu Aji Ngaliyan, khususnya atlet pemula agar terus berusaha meningkatkan ketepatan pukulan $l o b$ dalam bulutangkis, sehingga akan meningkatkan kemampuan dalam bermain bulutangkis dan berhasil mencapai prestasi yang maksimal.Bagi pelatih bulutangkis PB. Lindu Aji Ngaliyan, agar selalu memberikan program latihan yang baik dan efesien kepada atletnya, khususnya program latihan untuk meningkatkan ketepatan pukulan lob, yaitu dengan cara memberikan latiham pukulan lob berpola. Bagi peneliti selanjutnya, supaya menambahkan varibael lain selain variabel yang ada dalam penelitian ini, sehingga penelitian yang mengkaji tentang metode latihan untuk meningkatkan ketepatan pukulan lob dalam cabang bulutangkis dapat teridentifikasi lebih luas lagi.

\section{DAFTAR PUSTAKA}

Asnaldi, A. 2016. Hubungan Pendekatan Latihan Massed Practice Dan Distributed Practice Terhadap Ketepatan Pukulan Lob Pemain Bulutangkis. Jurnal Menssana, 1(2), 20-26.

Aksan, H. 2012. Mahir Bulu Tangkis. Bandung: Nuansa Cendikia.

Akbar, R., Hidasari, F. P., \& Haetami, M. 2017. Ketrampilan Teknk Dasar Servis, Lob dan Smash Bulutangkis Pada Ekstraskulikuler di Smp Negeri 18 Pontianak. 2.

Ahmad Ulil, D P. (2013). Perbedaan Hasil Latihan Umpan Balik Lob Langsung dan Lob Tak Langsung Terhadap Ketepan Lob Dalam Olahraga Bulutangkis di Pb Tugu Muda Kota Semarang (Doctoral dissertation, Universitas Negeri Semarang).

Republik Indonesia, 2005. Peraturan Pemerintahan nomor 3 Tahun 2005 Tentang Sistem Keolahragaan Nasional. Jakarta: Legalitas.

Rachman, T. N., Supriyadi, S., \& Surendra, M. 2019. Pengaruh Pola Latihan Overhead Clear Terhadap Kemampuan Teknik Pukulan Lob Bulutangkis Pada Peserta Ekstrakulikuler Sman 4 Malang. Jurnal Sport Science, 8(2).

Tohar, 1992. Olahraga Pilihan Bulutangkis. Semarang: IKIP Semarang 